\title{
Estimativa do consumo de combustível gasto com aquecimento de água em Manaus
}

\author{
Cleusa Maria Corrêa \\ Instituto Nacional de Pesquisos \\ da Amaxônia, Manaus
}

\section{INTRODUÇÃ̃o}

A grande preocupação da humanidade, no momento, é a escassez do petróleo e, ante a previsão de sua próxima exaustão, buscam-se novas alternativas energéticas e, entre estas, encontra-se a energia solar que é indicada para os países situados nos trópicos. Sendo o Brasil um dos grandes dependentes da importação de petróleo, para suprir as suas necessidades energéticas, qualquer economia desse produto será uma economia de divisas.

Atualmente no Estado do Amazonas, inclusive em Manaus, todos os sistemas geradores ce energia elétrica funcionam à base de derivados de petróleo.

No início da década de 60 (em 1962), inaugurou-se a primeira unidade termoelétrica em substituição à velha usina movida à lenha e a cidade saiu então da escuridão e do desconforto da falta de energia elétrica para uma situação mais privilegiada com relação a esse produto.

O funcionamento do mecanismo da Zona Franca ('), em 1967, proporcionou, entre outros fatores, um constante movimento de turistas na cidade, um grande afluxo de migrantes nacionais e estrangeiros, um maior dinamismo no comércio, o surgimento de um parque industrial, acelerando o crescimento urbano e populacional da cidade. Tais condicionantes causaram mudanças nos hábitos e costumes da população alargando conseqüentemente a cemanda do consumo da energia elétrica.

Em um levantamento feito entre a populaçăo urbana residencial e nos principais hotéis

(1) - Decreto n. 61.244 de 28 de agosto de 1967. Regulamenta o Decreto-Lei n. 288, de 28 de fevereiro de 1967. que altera as disposições da Lei n. 3.172 , de 6 de junho de 1957 e cria a Zona Franca de Manaus-SUFRAMA. 
da cidade, verificou-se através da existência de chuveiros elétricos e sistemas de aquecimento central, que uma parcela de energia elétrica é utilizada para obtenção de aquecimento de água para o conforto humano. O consumo de combustivel que é gasto com essa finalidade poderia ser plenamente substituído pela energia solar, que é uma técnica já consagrada, amplamente divulgada, utilizada em larga escala em outros países, e que também já vem sendo empregada com alguma regularidade na região Sul do País.

\section{ESTIMATIVA Nos HotÉrs}

Tomando como referência a relação dos hotéis divulgados pela EMAMTUR (Empresa Amazonense de Turismo), visitamos todos os hotéis em número de 35 , a fim de conhecer a situação dos mesmos quanto ao sistema de aquecimento existente. Do total de hotéis inqueridos, 22 que correspondem a uma capacidade de 2.589 pessoas, 19 possuem chuveiros elétricos nos apartamentos, 3 possuem aquecimento central com caldeiras a gás, óleo e elétricas, e 13 não possuem aquecimento de água para a higiene pessoal. Estes foram os hotéis enquadrados na classe turística B.

A situação dos hotéis quanto ao sistema de aquecimento existente encontra-se no Quadro I.

Admitindo-se a potência aproximada do chuveiro elétrico como de $2,5 \mathrm{~kW}$, a duração média de um banho de 10 minutos e a média de 2 banhos por dia, chega-se a um gasto de $0,825 \mathrm{kWh}$ por pessoa por dia. Baseado neste parâmetro, estimou-se o consumo de energia elétrica despendida, considerando os hotéis sempre lotados e todos os aparelhos sendo utilizados, como sendo da ordem de 360.000 kWh por ano o que vem corresponder a aproximadamente $108.000 \mathrm{~kg}$, ou 126.000 litros de óleo combustível por ano. Segundo dados fornecidos pela Companhia de Eletricidade de Manaus para gerar $1 \mathrm{kWh}$ são consumidos em média $0,300 \mathrm{~kg}$ de combustivel e que a $20^{\circ} \mathrm{C}$, $1 \mathrm{~kg}$ de óleo corresponde a 1,164 litros.

Um dos hotéis utiliza aquecimento central elétrico; para este estima-se um consumo de $21.000 \mathrm{kWh}$ por ano ou $6.000 \mathrm{~kg}$ de combustível por ano ou seja 7.000 litros por ano.

Para os hotéis que utilizam aquecimento por queima direta de óleo temos (tomando por base a mesma carga por banho por pessoa por dia) o consumo de $241.000 \mathrm{kWh}$ por ano correspondente a $72.000 \mathrm{~kg}$ por ano ou 84.000 litros por ano.

Os hotéis utilizando aquecimento de água através de queima de gás consomem 65.700 $\mathrm{kg}$ de gás por ano.

\section{ESTIMATIVA NAS RESIDENCIAS}

A primeira estimativa foi feita nas residências que possuem telefone, usando-se este mecanismo como veículo de coleta de informações, através de uma amostragem casuali-

QUADRO I - Situação dos hotéis de Manaus quanto ao sistema de aquecimento

\begin{tabular}{|c|c|c|c|c|}
\hline Especificação & n. de hotéis & $\begin{array}{l}\text { n. total de } \\
\text { apto. }\end{array}$ & $\begin{array}{l}\text { n. de chuveiros } \\
\text { elétricos }\end{array}$ & $\begin{array}{l}\text { Lotação máxima } \\
\text { por pessoas }\end{array}$ \\
\hline Hotéis com chuveiros elétricos............ & 19 & 644 & 598 & 1.325 \\
\hline 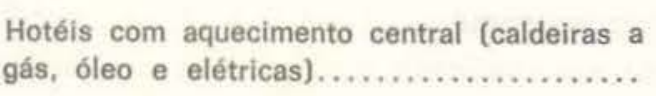 & 3 & 845 & - & 1.264 \\
\hline Totais............... & 22 & 1.489 & 598 & 2.589 \\
\hline
\end{tabular}

Dados de nov, de 1979 
zeda por etapa dupla onde foram sorteadas 50 ruas, abrangendo diversos bairros, ruas centrais tradicionais e conjuntos residenciais e, nas ruas sorteadas, 500 telefones residenciais que comporiam a amostra. Para a seleção da unidade amostral, foi utilizado o Catálogo Te lefônico do Amazonas de 1979.

Das 500 residências consultadas, 146 ou seja $29 \%$ das pessoas informaram possuir chuveiros elétricos em casa, havendo residências com mais de 1 chuveiro elétrico aparecendo no máximo 3 (10 residências) dando um total de 198 chuveiros com uma média para estas residências de 1,4 $\pm 0,2$.

$\mathrm{O}$ número de pessoas residindo nas moradias onde existiam chuveiros elétricos foi de 753 pessoas com uma média de 5,2 $\pm 2,3$.

Das 146 pessoas informantes 17 afirmaram que os chuveiros estavam com defeito por ocasião da consulta e 12 informaram que possuem mas não usam o chuveiro elétrico. $\mathrm{O}$ total com defeito acrescido dos não utilizadios somam 29 que representam $15 \%$ do total de chuveiros elétricos existentes.

Considerando o número de telefones resicienciais de Manaus até novembro de 1979 de cerca de 16.087 (dados fornecidos pela TELAMAZON, Telecomunicações do Amazonas S.A.), teremos com base nas informações encontradas, tomando-se o número médio de pessoas por residência e utilizando os mesmos parâmetros e pressupostos já indicados anteriormente, de que são consumidos $7.300 .000 \mathrm{kWh}$ por ano de energia elétrica ou seja 2.155.000 $\mathrm{kg}$ de combustível, perfazendo $2.500 .000 \mathrm{li}$ tros por ano para aquecimento de água.

Foi realizado também um pequeno inquérito, a título de observação numa amostragem não probabilística em um dos bairros periféri$\cos$ de Manaus onde foram sondadas 60 residências sem telefones, não se verificando a existência de chuveiros elétricos.

Em resumo, a estimativa do consumo total máximo de kWh gasto para aquecimento em Manaus entre os usuários analisados neste estudo, foi da ordem de 7.927.000 kWh por ano, que vem corresponder a, aproximadamente, $2.233 .000 \mathrm{~kg}$ de óleo ou seja $2.725 .000 \mathrm{li}$ tros por ano.

Em Manaus, pesquisas demonstraram que a radiação solar global média do ano é da or. dem de $430 \mathrm{cal}$ por $\mathrm{cm}^{-2}$ por dia - ${ }^{-1}$ (Villa Nova et al, 1978), podendo-se obter em coletores planos uma eficiência máxima em torno de $57 \%$ (Almeida \& Harwood). Experiências com 3 aquecedores solares domésticos de placas planas de $3 \mathrm{~m}^{2}$ cada um, demonstraram que é possível obter-se para as necessidades de uma família média na maior parte do ano água quente a $60^{\circ} \mathrm{C}$ (Almeida \& Harwood). Estas informações indicam que seria possível economizar praticamente toda a energia elétrica que é utilizada para aquecimento de água residencial e em hotéis com um programa de implantação de aquecedores solares em Manaus.

Segundo Enéas Salati $\left({ }^{2}\right)$, nos casos de hotéis que produzem vapor de água a alta temperatura será possível uma economia da ordem de $10 \%$ do consumo de óleo, mediante préaquecimento .

É necessário ressaltar que Manaus estando situada em plena zona equatorial, talvez a freqüência de uso de chuveiros elétricos por fessoa, esteja superestimada, bem como a constante lotação dos hotéis seja um dado um tanto exagerado, entretanto o objetivo do estúdo foi chegar a um consumo máximo para que a partir daí se inferissem outras estimativas.

Não obstante, esta superestimativa também está amenizada pela certeza de não termos um levantamento completo da população, pois foi analisada apenas uma parcela do universo.

É provável que o consumo tenderá a crescer em futuro próximo dada a constante expansão urbana da cidade com a construção de novos conjuntos residenciais e novos hotéis.

Convém salientar que há um esforço muito grande na região Sul do País para a utilização de aquecedores solares em coletores planos, existindo fábricas com produção em série.

(2) - Informações pessoais. 


\section{SUMMARY}

The future wordwide depletion of petroleum de. posits constitutes nowadays a serious concern for all mankind. Consequently, this feared demise of ease and inexpensive oil, has spurred interest on the search for others energy alternatives.

A sarvey carried out within urban households and hotels in Manaus showed that a part of its energy consumption is used to heat water for human confort. Shifting to solar energy from the present system of water heating - which is based on electrity, butane gas and fueloil - would bring about substantial savings in fossil fuels. Existing local experiments have shown this substitution to be satisfatory.

\section{BIBLIOGRAFIA}

ALMEIDA, RONALDO \& HaRWOOD, JohN H.

- Desempenho de um aquecedor solar de água em Manaus (em preparação).

Villa Nova, N.A.; Góes Ribetro, M.N.; Nobre, G.A. \& SALATI, E.

1978 - Radiaçẫo Solar em Manaus. Acta Amazonica, 8 (3): $417-421$.

(Aceito para publicação em $15 / 10 / 80$ ) 